\title{
A study of consumer preferences for customized product design
}

\author{
Endang Retno Wedowati ${ }^{1,2, *}$, Moses Laksono Singgih ${ }^{3}$, and I Ketut Gunarta ${ }^{3}$ \\ ${ }^{1}$ Doctoral Student at Department of Industrial Engineering, Institut Teknologi Sepuluh Nopember \\ (ITS), 60111 Surabaya, Indonesia \\ ${ }^{2}$ Universitas Wijaya Kusuma Surabaya (UWKS), 60225 Surabaya, Indonesia \\ ${ }^{3}$ Department of Industrial Engineering, Institut Teknologi Sepuluh Nopember (ITS), 60111 \\ Surabaya, Indonesia
}

\begin{abstract}
Segmentation has been frequently used to study individual consumer behavior against its preference. Consumer preferences indicate consumer requirements for a product. This study aims to analyze consumer preferences based on gender segmentation (male and female) and age segmentation (adolescents, adults, and elderl y). Consumer preferences wer e studied based on three aspects, namely functionality, usability, and pleasure that are applied to food products. Respondents consisted of 225 consumers of ice cream products. Crosstab analysis was used to describe consumer preferences, while chi-square test was applied to analyse the difference of consumer preference based on predetermined segmentation. The result showed that there was no significant difference for male and female consumer preferences for three aspects. Furthermore, on the attributes of taste (functionality), shape (usability) and appearance (pleasure) there were significant differences. Based on the age segmentation there were differences in consumer preferences for aspects of functionality and pleasure. Howe ver, we also found that there was no significant difference in product attributes of those aspects, except for the colour attribute. Different consumer preferences obtained in different segments can be used as a reference to customer requirements for design ing customized products. Ultimately, the products can be tailored to consumer preferences in each segment.
\end{abstract}

\section{Introduction}

Market segmentation was done to determine the right target consumers. Market segmentation can be based on demographic segmentation, geographic segmentation,

\footnotetext{
*Corresponding author : wedowati77@gmail.com, wedowati@uwks.ac.id
} 
psychographic segmentation, an d behavioural segmentation [1]. Demographic segmentation are age, gender, and income; geographic segmentation are country, region, and city; psychographic segmentation are values adopted by consumers and lifestyles; and finally behavioural segmentation is consumer behaviour towards a product. In this study, the segmentation studied is demographic segmentation based on gender and age segments to analyse differences in consumer preferences for food products, especially ice cream products.

Research related to segmentation of gender and age in food product among others done by [2]. The results of this study indicate that there are differences in consumer preferences both on the gender segment and age segment to the sensory properties of wine products. Lifestyle segmentation is used by [3] to examine consumption patterns of local and organic food. Segmentation based on psychographic segmentation is done by [4] to examine the effects of food neo-phobia (avoid new foods) to the acceptance of new foods.

To design products, producer must pay attention to consumer preferences to the attributes. Food products attributes are generally grouped into two types of attributes, namely intrinsic attributes and extrinsic attributes [5]. The intrinsic attribute is quality of a product based on the function and physical properties of the product, while extrinsic attributes are aspects related to the product but there are physically not part of the product itself.

Several previous studies have conducted studies on the attributes of product quality in food products, both intrinsic and extrinsic attributes. Among them is [6] review food product attributes based on intrinsic attributes that include colour, aroma, taste and texture, as well as extrinsic attributes that include brand, price and context. Other than that, [7] have examined the attributes of traditional food products, which include intrinsic attributes (colour, taste, aroma, appearance) and extrinsic attributes (brand, denomination of origin, and traditional product image); [8] examines dry-cured ham products based on intrinsic attributes (appearance, smell, taste, texture) and extrinsic attributes (price, nutritional value and processing conditions); [9] examines the onion concentrate product attributes based on flavour, aroma and texture; also [10] review fruit juice products based on extrinsic attributes of brand, ingredients label, shelf-life, price, and manufacturing countries.

One of the consumer preferences is pleasurable design, where product attributes are based on three aspects, namely aspects of functionality, usability, and pleasure [11]. The pleasurable design involves human element to design products in order to meet expectations of consumers. The fulfillment of these consumer expectations will increasing customer satisfaction and will establish customer loyalty [5, 13].

Functionality aspect is the most basic aspect demanded by consumers, namely the ability of the product in fulfilling its function. The second aspect after functionality aspect is usability aspect, i.e., easiness to consume. The third aspect is pleasure aspect, i.e., extra attributes possessed by the product, not only functional benefits but also related to the emotional aspect of the consumers.

\section{Methods}

Data were collected using questionnaire through social media i.e., facebook. Social media is used so that only interested respondents who fill out the questionnaire. The target respondents were consumers of ice cream of adolescent, adult, and elderly group. The distribution of questionnaire is limited within a month. Within a month of questionnaire distribution, obtained 225 respondents who responded. 
Questionnaire is organized into two parts, the first part relates to the demographic aspects of respondents, namely gender (male and female) and age. Age is grouped into three categories based on age categories according to the Ministry of Health of the Republic of Indonesia, 2009 [13], there are adolescents (12-25 years), adults (26-45 years), and elderly (46-65 years). While the second part related to consumer preferences for ice cream products. Consumer preferences in this study is based on aspects of functionality, usability, and pleasure.

Based on functionality aspects, the attributes reviewed include taste, colour, aroma, and nutritional content. Based on usability aspect, the attribute reviewed is shape of ice cream. While based on pleasure aspects, the attributes reviewed include health benefits, appearance, and type of toppings.

The collected data was analyzed using crosstab analysis and chi-square test. The results of the analysis can be presented in numerical or graphical form [14]. Crosstab analysis is used to describe the relationship between two categorical variables, where one variable is defined as a row and the other variable as a column. Table dimension is denoted as $\mathrm{RxC}$, where $\mathrm{R}$ is the number of categories for the Row variable and $\mathrm{C}$ is the number of categories for the Column variable [15].

In addition to crosstab analysis, a chi-square test was performed to differentiate consumers' preferences by gender and age segmentations. This test is performed on attributes in every aspect and variant in each attribute. The degree of confidence used in the chi-square test is $10 \%$.

\section{Results and Discussion}

Novelty of this research is consumer preference review based on pleasurable design which cover three aspects, that is aspect of functionality, usability, and pleasure. Where in general research related to food products use the perception of intrinsic and extrinsic attributes. The results of crosstab analysis were used to describe the attributes that consumers want on ice cream products based on gender and age segmentation. While the results of chi-square analysis used to determine whether there was a significant difference to consumer preferences based on gender and age segmentation, on aspects and attributes that consumers want in ice cream products.

Segmentation based on gender and age has been widely practiced, among others by [2] in assessing consumer preferences related to sensory properties in wine products. Result of chi-square test for the three aspects can be seen in Table 1.

Consumer preferences are important to design products for targeted segments. Products tailored to the needs and wants of consumers, so as to meet the desires of consumers. This concept is in accordance with the concept of mass customization (MC), where consumers can choose the product design in accordance with the required attributes [16]. Customer involvement in the design is a major determinant of the level of personalization that can be offered by the concept of MC [17]. The concept of MC offers a trend in the future where consumer choice in the form of customized products can be responded quickly [18, 19]. In addition, food product attributes can form valuable market segmentation, as they relate to health perceptions and product sustainability [20]. 
Table 1. Chi-square tests based on gender and age segmentations.

\begin{tabular}{|c|c|c|c|c|c|c|c|}
\hline \multirow{2}{*}{ Aspects } & \multirow{2}{*}{ Attributes } & \multicolumn{3}{|c|}{ Gender Segmentation } & \multicolumn{3}{c|}{ Age Segmentation } \\
\cline { 3 - 8 } & & $\chi^{\mathbf{2}}$ Value & Sig. & Result & $\chi^{\mathbf{2}}$ Value & Sig. & Result \\
\hline Functionality & & 4.092 & 0.402 & No Significant & 13.843 & 0.086 & Significant \\
\hline \multirow{2}{*}{} & Taste & 34.293 & 0.003 & Significant & 39.341 & 0.118 & No Significant \\
\hline & Colour & 12.665 & 0.243 & No Significant & 37.516 & 0.010 & Significant \\
\hline \multirow{2}{*}{ Usability } & Aroma & 12.619 & 0.351 & No Significant & 19.539 & 0.612 & No Significant \\
\hline & $\begin{array}{c}\text { Nutrition } \\
\text { Content }\end{array}$ & 6.276 & 0.179 & No Significant & 9.041 & 0.339 & No Significant \\
\hline \multirow{2}{*}{ Pleasure } & Shape & 18.797 & 0.005 & Significant & 9.198 & 0.686 & No Significant \\
\hline & & 2.492 & 0.646 & No Significant & 15.219 & 0.055 & Significant \\
\hline & $\begin{array}{c}\text { Health } \\
\end{array}$ & 4.374 & 0.736 & No Significant & 18.467 & 0.186 & No Significant \\
\hline & Appearance & 13.440 & 0.098 & Significant & 16.237 & 0.437 & No Significant \\
\hline & Toppings & 16.658 & 0.340 & No Significant & 35.603 & 0.221 & No Significant \\
\hline
\end{tabular}

\subsection{Gender Segmentation}

Based on Chi-square test, it can be explained that the three aspects are reviewed, namely the aspect of functionality, usability, and pleasure, there were no significant differences between consumer preferences of male and female. However, there were significant differences in the attributes of taste (functionality aspect), shape (usability aspect), and appearance (pleasure aspect), as shown in Table 1.

Based on Crosstab analysis, for the aspect of functionality, the attributes required by male consumers in sequence are taste, texture, nutritional content, colour and aroma, while the preferences of female consumers include taste, texture, and nutritional content. Of the existing attributes, only the taste attributes differ significantly between male and female consumer preferences ( $\mathrm{Sig}=0.003<\alpha=0.1$ ).

Taste attribute was the most preferred attributes for both male and female consumers, respectively

by $61.0 \%$ and $65.6 \%$. The taste is a key driver for consumer preferences for food products [21]. However, related variants of taste of ice cream there were differences in consumer preferences of male and female. In addition to chocolate, female consumers prefer vanilla than other taste, but male consumers prefer durian. The four highest taste variants of interest to male consumers are chocolate, durian, vanilla, and strawberry, while the interest to female consumers are chocolate, vanilla, strawberry, and blueberry. Another variant that male consumer wants are caramel and watermelon, whereas female consumers' wants are apple, grapes, mocha, and green tea.

Based on Crosstab analysis there was known that for the usability aspect, the top three attributes 
desired by the male and female consumers in sequence are not different, namely packaging material, information about the expiry date, and shape. In addition to these three attributes, the other attributes that consumers want include attributes of size, labels, information about how to consume, information about benefits, and information about how to save. Of the existing attributes, only the shape attribute was differed significantly between the preferences of male and female consumers ( $\mathrm{Sig}=0.005<\alpha=0.1$ ).

Packaging material attribute was the attribute most preferred by consumers, but there was no significant difference between male and female consumer preferences. Differences in consumer preferences of male and female was in shape attribute. The order of ice cream shapes that male consumers wants are cone, cup, stick, pack, and sandwich. Meanwhile, the order of ice cream shapes that female consumer interests are cone, cup, pack, stick, and sandwich.

Based on the analysis of Crosstab there was known that for the aspect of pleasure, the attributes required by male consumers in sequence are health benefits, brand/image, appearance, and packaging design, while the preferences of female consumers include health benefits, appearance, brand/image, packaging design, and innovation.

From the five attributes, only the appearance attribute differs significantly between male and female consumer preferences ( $\mathrm{Sig}=0.098<\alpha=0.1$ ). Appearance of ice cream of the most preferred by male consumers was wrapped in chocolate sauce and peanut. Then followed by the appearance of ice cream wrapped in chocolate sauce and ice cream with toppings. Toppings that male consumers choose are chocolate, almond and cashew granules. While the appearance of ice cream was most preferred by female consumers, namely ice cream wrapped in chocolate sauce, ice cream with pieces of various fruits, ice cream wrapped in chocolate sauce and peanut, and ice cream with toppings. Toppings of interest to female consumers are almonds granules, chocolate granules, and chocolate sauce.

\subsection{Age Segmentation}

Based on chi-square test, there was known that the three aspects are reviewed, namely the aspect of functionality, usability, and pleasure, only the usability aspect was no significant differences between consumer preferences of adolescents, adults and elderly. While on aspects of functionality and pleasure were significant differences. However, there was no significant differences on all attributes reviewed except the colour attribute. Result of chi-square test for the three aspects can be seen in Table 1.

Based on Crosstab analysis there was known that for the aspect of functionality, the attributes desired by the adolescent consumer in sequence are taste, texture, nutritional content, and colour, adult consumer preferences include taste, nutritional content, texture, colour, and aroma, while the elderly consumer preferences are taste, nutritional content, and texture. Preferences of adolescent, adult, and elderly consumers differ significantly to aspect of functionality ( $\mathrm{Sig}=0.086<\alpha=0.1$ ). But there is no significant difference for the required variant in each attribute, except for the colour attribute.

Adult and elderly consumers, in addition to attribute of taste of preferring the attribute of nutritional content than texture. In contrast to the preference of adolescent consumers who are more concerned with texture attribute than the nutritional content. Adult and elderly consumers are more concerned with the content of nutrients because for this age segment of the nutritional content can be associated with health benefits that can be derived from a food product. This is consistent with that presented by [20] that the attributes of food products based on market segmentation can be related to health perception. 
Consumer preferences based on age segmentation for colour attributes differ significantly. The top three colours of ice cream selected by adult and elderly consumers are chocolate, white and beige, while the colour variant of adolescent consumers selected are brown, white, and red. In addition to these three colours, for adolescent consumer also want the colour of beige, blue, green, purple, and yellow. The colour choices of adolescent consumers are more colourful.

Based on Crosstab analysis there was known that for usability aspect, the top three attributes desired by adolescent consumer are packaging materials, shape, and information about the expiration period. Adult consumers are more concerned about the attributes of expiry date information and then followed by packaging materials and shape attributes. While the elderly segment sequentially selects attributes of packaging material, expiry date information, and shape. In addition to these three attributes, other attributes that consumers wants include attribute of size, information about benefits, labels, information about how to consume, and information about how to save.

Consumer preferences based on age segmentation, did not show any significant differences in

aspect of usability, there was indicated by the value of Sig=0.589 $>\alpha=0.1$. Similarly, for shape attribute, of the three age segments have preference that was not significantly different ( $\mathrm{Sig}=0.686>\alpha=0.1$ ). However, there were different preference sequences related to this shape attribute. Adolescent and adult consumers tend to have a common preference of ice cream shape. Three variants of the ice cream shape of the most in demand by consumers of adolescents and adults are cone, cup and stick. While elderly consumers prefer the shape of cup, cone, and pack.

Based on Crosstab analysis there was known that for the aspect of pleasure, the attributes required by the adolescent consumer in sequence are health benefits, appearance, brand/image, and packaging design, adult consumer preferences include health benefits, brand/image, appearance and packaging design, while the elderly consumer preferences include health benefits, brand/image, appearance, packaging design, and innovation.

Consumer preferences of adolescents, adults and elderly were significantly different to the aspect of pleasure ( $\operatorname{Sig}=0.055<\alpha=0.1$ ). But there was no significant differences for the desired variant in each attribute, either on the attributes of the health benefits, appearance, and type of toppings. In addition to health benefits attribute, adult and elderly consumers prefer brand/image attribute rather than product appearance attribute. In contrast, adolescent consumer prefers the attribute of appearance rather than brand/image attribute. Therefore, for adolescent segment, ice cream product design should be given priority to product appearance, where product design was made as attractive as possible.

\section{Conclusion}

A survey has been conducted to a group of respondents to investigate consumer preferences for ice cream products. Two segmentations were determined beforehand gender and age. The study has found that different gender did not show any significant difference in the selection of product attributes for the three aspects reviewed that include functionality, usability, and pleasure. However, there was a significant difference in variant preferences for attributes of taste (functionality), shape (usability), and appearance (pleasure).

Based on age segmentation, adolescents, adult and elderly have shown different preferences in aspects of functionality and pleasure, but not significantly different for usability aspect. Similarly, there is no significant difference in product attributes in every aspect, except for colour attribute. Adult and elderly consumers prefer classic colors, while adolescent consumer choose more varied colors. In functionality aspect, in 
addition to taste attribute, attribute of nutritional content of product becomes demanded by adult and elderly consumers. While in the aspect of pleasure, in addition to the attribute of health benefits, the brand/image attribute is preferred by adult and elderly consumers, but for adolescent consumer prefer the appearance attribute.

Based on the results of consumer preferences obtained in each segment, in designing customized product, it is important to note the attributes in each aspect according to consumer preferences, so the product can be designed based on targeted market segments. Furthermore, the ice cream products can be designed refer to customer requirement on each segment as customized products. For the male consumer segment, the taste attribute is more geared towards classic taste, such as chocolate and vanilla, while the female consumer in addition to the classic taste also required ice cream products with fruit taste. For adult and elderly consumer segments, the colour attribute is directed at classic colours, but for adolescent consumer other than classic colours need to be designed products with more varied colours.

Acknowledgments to the Ministry of Research, Technology and Higher Education of the Republic of Indonesia which has funded this research through Doctoral Dissertation Research Grant with contract number $008 / \mathrm{SP} 2 \mathrm{H} / \mathrm{LT} / \mathrm{K} 7 / \mathrm{KM} / 2018$.

\section{References}

1. N. Larsen, Aarhus School of Business, (2010)

2. M. Mora, E. Urdaneta, C. Chaya, Food Qual. Prefer, 66 (2018)

3. C. Nie and L. Zepeda, Appetite, 57 (2011)

4. A. S. Henriques, S. C. King, H. L. Meiselman, Food Qual. Prefer, 20 (2009)

5. C. Fandos and C. Flavián, Br. Food J., 108 (2006)

6. R. Iop, S.C.F., Teixeira, E., Deliza, Br. Food J., 108 (2006)

7. J. Espejel, C. Fandos, C. Flavián, Manag. Serv. Qual, 17 (2007)

8. M. Hersleth, E. Monteleone, A. Segtnan, T. Næs, Food Qual. Prefer, 40 (2015)

9. T. Nishimura, A. Saiga, A. Nagao, T. Odahara, T. Sugise, N. Mizoguchi, Y. Nosho, Food Chem, 192 (2016)

10. P. Y. Lee, K. Lusk, M. Mirosa, I. Oey, Food Qual. Prefer, 46 (2015)

11. P. W. Jordan, Designing Pleasurable Products, (2000)

12. V. Stan, B. Caemmerer, R. Cattan-jallet, J. Appl. Bus. Res., 29 (2013)

13. Anonim, Depkes-RI, (2009)

14. S. Jaggi, Indian Agric. Stat. Res. Inst., (2003)

15. K. S. U. Libraries, Kent State University Libraries, (2017)

16. S. Fogliatto and J. C. Giovani, Int. J. Prod. Econ., 111 (2008)

17. R. Duray, Int. J. Oper. Prod. Manag., 22 (2002)

18. S. M. Davis, Future Perfect, (1987)

19. B. J. Pine, B. Victor, A. C. Boynton, Harvard Business Review, (1993)

20. M. C. D. Verain, S. J. Sijtsema, G. Antonides, Food Qual. Prefer., 48 (2016)

21. S. De Pelsmaeker, J. J. Schouteten, S. Lagast, K. Dewettinck, X. Gellynck, Food Qual. Prefer, 62 (2017) 